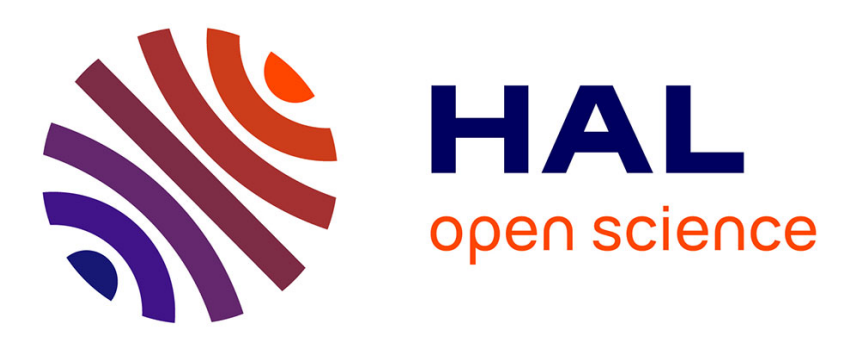

\title{
MDF treatment with a Dielectric Barrier Discharge (DBD) torch
}

\author{
Frederic Perisse, S. Menecier, E. Duffour, D. Vacher, G. Monier, J.-F
}

Destrebecq, P. Czarniak, J. Górski, J. Wilkowski

\section{To cite this version:}

Frederic Perisse, S. Menecier, E. Duffour, D. Vacher, G. Monier, et al.. MDF treatment with a Dielectric Barrier Discharge (DBD) torch. International Journal of Adhesion and Adhesives, 2017, 79, pp.18 - 22. 10.1016/j.ijadhadh.2017.09.006 . hal-01653269

\section{HAL Id: hal-01653269 https://hal.science/hal-01653269}

Submitted on 10 Jan 2018

HAL is a multi-disciplinary open access archive for the deposit and dissemination of scientific research documents, whether they are published or not. The documents may come from teaching and research institutions in France or abroad, or from public or private research centers.
L'archive ouverte pluridisciplinaire HAL, est destinée au dépôt et à la diffusion de documents scientifiques de niveau recherche, publiés ou non, émanant des établissements d'enseignement et de recherche français ou étrangers, des laboratoires publics ou privés. 


\title{
MDF treatment with a Dielectric Barrier Discharge (DBD) Torch
}

\author{
F. Perisse ${ }^{\mathrm{a}}$, S. Menecier ${ }^{\mathrm{a}}$, E. Duffour ${ }^{\mathrm{a}}$, D. Vacher ${ }^{\mathrm{a}}$, G. Monier ${ }^{\mathrm{a}}$, J.-F.Destrebecq ${ }^{\mathrm{a}}$, \\ P. Czarniak ${ }^{\mathrm{b}}$, J. Górski ${ }^{\mathrm{b}}$, J. Wilkowski ${ }^{\mathrm{b}}$ \\ ${ }^{a}$ Université Clermont Auvergne, CNRS, Institut Pascal, F-63000 CLERMONT-FERRAND, FRANCE, \\ ${ }^{b}$ Warsaw University of Life Science Faculty of Wood Technology
}

\begin{abstract}
A Dielectric Barrier Discharge (DBD) Torch has been designed for the treatment of several wood species and composites. This paper presents some results obtained onto Medium Density Fiberboard (MDF) samples. The aim of the treatments was to improve their wetting properties. Tests made before and after treatments showed improvements of surface wetting and have been correlated with surface chemical composition. It also has been shown that the treatment effect is ephemeral.
\end{abstract}

Keywords: Dielectric Barrier Discharge, wood, wettability, O/C ratio

\section{Introduction}

Medium density fiberboard (MDF), which is a particular composite forest product (consisting of cellulosic fibers and synthetic resin bonded together), was invented in the United States in the 1960's as a solid wood substitute. Nowadays, MDF is globally produced on a large scale and widely used in various industries. For example, it is one of the most important and popular materials used in furniture manufacturing, mainly because it can be easily and precisely machined to form complex shapes. This is a result of the fact that MDF is free of structural defects (e.g. knots, shakes or checks) and does not contain any rings, which makes it more uniform, stabile and isotropic than natural wood or plywood. Moreover, it is far more homogeneous than most of other wood-based materials (e.g. ordinary chipboards). In present day, there are a lot of well-known industrial and non-industrial ways of MDF surface finishing (wet painting, powder coating, veneer, melamine, paper or plastic foils, HPL/CPL laminate...), which determine the quality of final products. Regardless of the finishing technology, the wettability of MDF surface plays a crucial role. The positive correlation between wettability and adhesive properties of wood and wood-based materials is evident [1-7].

Corresponding author

Email addresses: Frederic.perisse@uca.fr (F.Perisse ), pczarniak63@o2.pl (P. Czarniak) 
Poor adhesion causes higher costs of surface finishing. Therefore, the problem of wettability of commercial or experimental MDF has been the subject of numerous scientific studies. It is worth noting that poor bonding ability and wettability occurs especially in the case of MDF manufactured from thermally treated fibers [8] which was subjected to the post-manufacture heat-treatment. These techniques are considered advantageous due to the increase in dimensional stability, fungal resistance and surface smoothness of wood [9]. One of the most promising (from practical point of view) methods of improving the adhesive properties as well in case of MDF [8-10] as in case of Wood Plastic Composites (WPC) surface [11-12] is plasma treatment, but really effective implementation of this method needs further both basic and applied research. This present study is a part of this trend of scientific activity.

\section{Experimental setup and analytical devices}

\subsection{DBD Torch}

The plasma apparatus is shown in Figure 1. The geometry of the Dielectric Barrier Discharge (DBD) is fixed and detailed in Figure 2. The DBD torch was designed in the laboratory, the dielectric used is Pyrex ${ }^{\circledR}$, the total area of the discharge is about $19 \mathrm{~cm}^{2}$, and all external parameters are variable within the following ranges:

- Frequency $f$ : [10-35 kHz] with duty cycle $\alpha$ of $45 \%$.

- DBD Voltage $u$ : [0-15 kV]

- Gas flow : [0-100 L.min $\left.{ }^{1}\right]$

- Movement speed (Wood / DBD torch): [1-100 mm.s $\left.{ }^{-1}\right]$

In these conditions, the electrical power of DBD torch is approximately $150 \mathrm{~W}$. The MDF samples of $50 \times 60 \mathrm{~mm}^{2}$ and $1 \mathrm{~cm}$ thick are placed on a XY table. The sample moves under the torch at fixed velocity, as close as possible to the torch exit (about $1 \mathrm{~mm})$.

\subsection{Analyses methods}

\subsubsection{Sessile drop method}

Wettability of the MDF surface is evaluated through the contact angle of a water drop put on its surface. One calibrated drop of water is put on the MDF surface. A camera is used to photograph the system. ImageJ software is used to determine both, right and left angle. Final contact angle is the average of the two values. Since the drop on the surface is progressively absorbed by the wood, the contact angle measured varies with time. Therefore, all the measurements were made $30 \mathrm{~s}$ after putting the drop onto the surface. A preliminary study was done to evaluate uncertainty of this method on the contact angle value. 10 drops were put with homogeneous distribution on an untreated MDF sample. Several pictures of each drop were taken and several drop contour fittings were led on each picture. Enlarged uncertainty with a confidence interval of $99 \%$ was found to be $9^{\circ}$. 


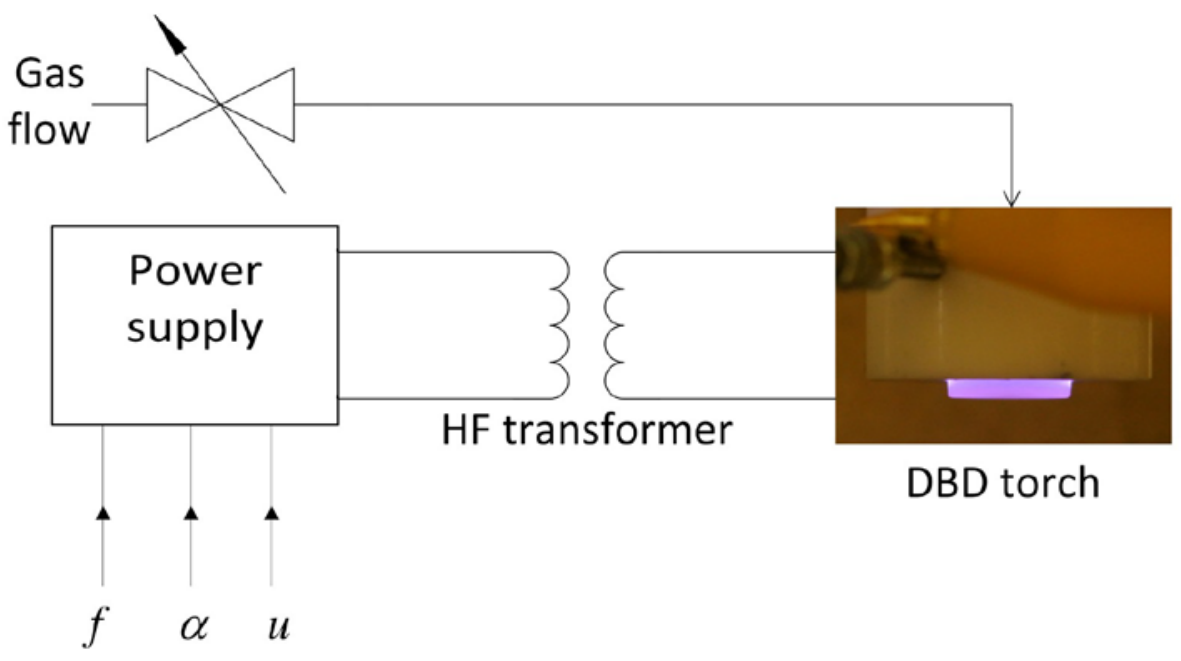

Figure 1: Global view of the process device

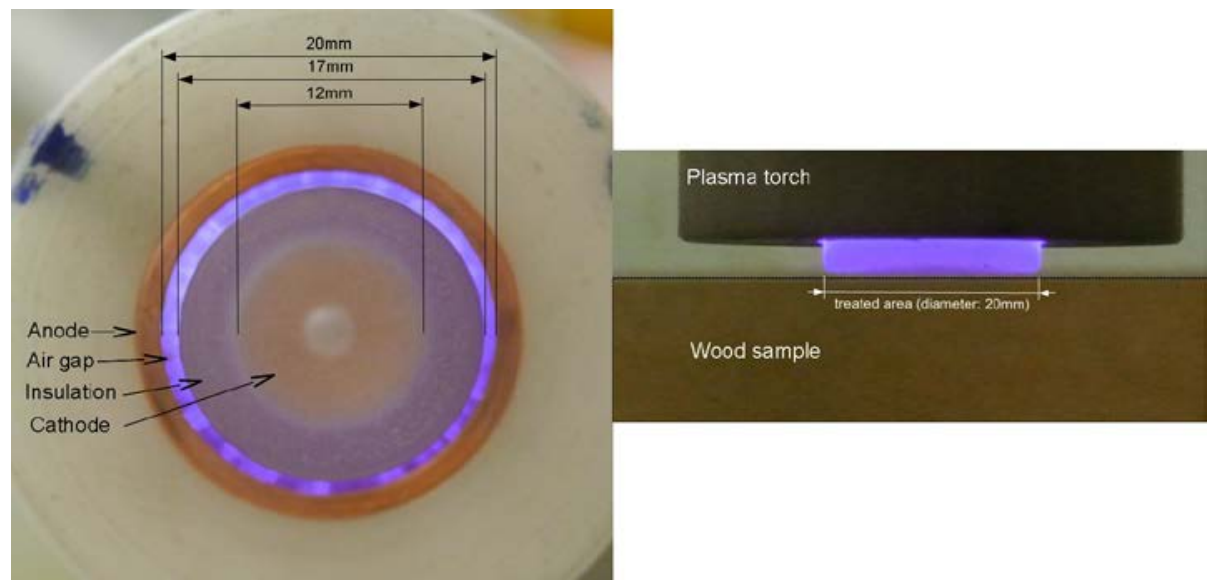

Figure 2: The Dielectric Barrier Discharge Torch (underneath view on the left panel and cross view on the right panel)

\subsection{2. $X P S$}

Compositions of surface samples were analyzed by XPS. These experiments were carried out in an UHV chamber equipped with a XPS system (dual anode Al-Mg Xray source and hemispherical electron energy analyzer OMICRON EA125). Mg K $\alpha$ source $(1253.6 \mathrm{eV})$ at an incident angle of $55^{\circ}$, normal detection and pass energy of the analyzer equal to $20 \mathrm{eV}$ were used for analysis. It must be noted that XPS analysis needed 24 hours of pumping to provide an adequate vacuum for the XPS analysis. The effects of vacuum on the evolution of the wetting properties were not studied.

\section{Results}


The DBD torch was used with a nominal secondary voltage of $8 \mathrm{kV}$ and $1 \mathrm{~mm}$ away from the MDF samples. The treatment consisted in passing the samples 3 times under the DBD torch. A parametric study was firstly achieved to determine the impacts of treatment speed, air flow and electrical frequency on the wetting properties of MDF. Once the most relevant parameters had been identified, a more detailed study has been led to focus on the impact of the passes number. For those second tests campaign, XPS analyses were achieved on the samples in view to estimate surface compositional changes.

\subsection{Parametric studies}

With a voltage of $8 \mathrm{kV}$, frequency of $25 \mathrm{kHz}$ and an air flow of $70 \mathrm{~L} / \mathrm{min}$, MDF samples were moved 3 times under the DBD torch with different speed treatments from 1 to $100 \mathrm{~mm} \cdot \mathrm{s}^{-1}$. Once the treatment was achieved, the contact angle was measured. The results are shown in Figure 3. The results show that the slower the treatment speed, the better the treatment result. Indeed, a treatment speed of $100 \mathrm{~mm} . \mathrm{s}^{-1}$ is ineffective since the contact angle after treatment remains the same as before. In the opposite, for the lowest speed used $\left(1 \mathrm{~mm} . \mathrm{s}^{-1}\right)$, the contact angle decreases from $106^{\circ}$ before treatment to $50^{\circ}$ afterwards. This result seems to be very intuitive; the slowest treatment brings more energy to the MDF surface. For the next experiments, the treatment speed was therefore settled to $1 \mathrm{~mm} \cdot \mathrm{s}^{-1}$.

The study of the influence of the airflow in the DBD torch was led with again same voltage and frequency and with a treatment speed of $1 \mathrm{~mm} \cdot \mathrm{s}^{-1}$. Airflow was varied from 50 to $80 \mathrm{~L} \cdot \mathrm{min}^{-1}$. The four experiments presented in Figure 4 show that the treatments results are still very good (maximum contact angle is $56^{\circ}$ instead of $21^{\circ}$ for untreated samples) but best for the airflow of $70 \mathrm{~L} \cdot \mathrm{min}^{1}$. It has to be noticed that even lower air flow were tried, but led to arcing phenomena in the torch. It seems that the process demands high electrical mass energy transfer to air, but a too large energy per mass unit of air can lead to arc formation and deterioration of the torch. Airflow of $70 \mathrm{~L} \cdot \mathrm{min}^{-1}$ was then chosen for next experiments.

The impact of electrical frequency was then studied with the previously chosen parameters and a frequency ranging from 20 to $35 \mathrm{kHz}$. Results are presented in Figure 5. Whatever the frequency used, the treatment remains very efficient as the contact angle decreases from $121^{\circ}$ for the reference to a value between $56^{\circ}$ and $75^{\circ}$. 


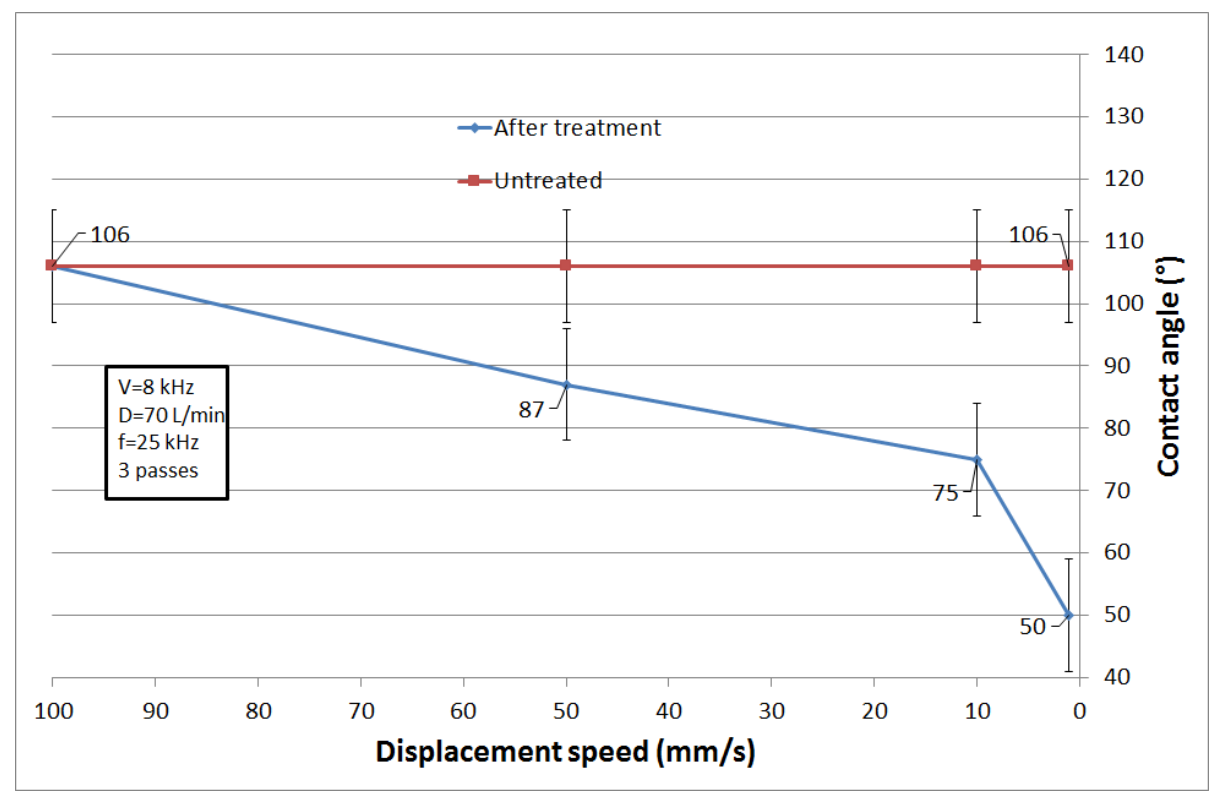

Figure 3: Influence of the treatment speed on the wetting properties of MDF

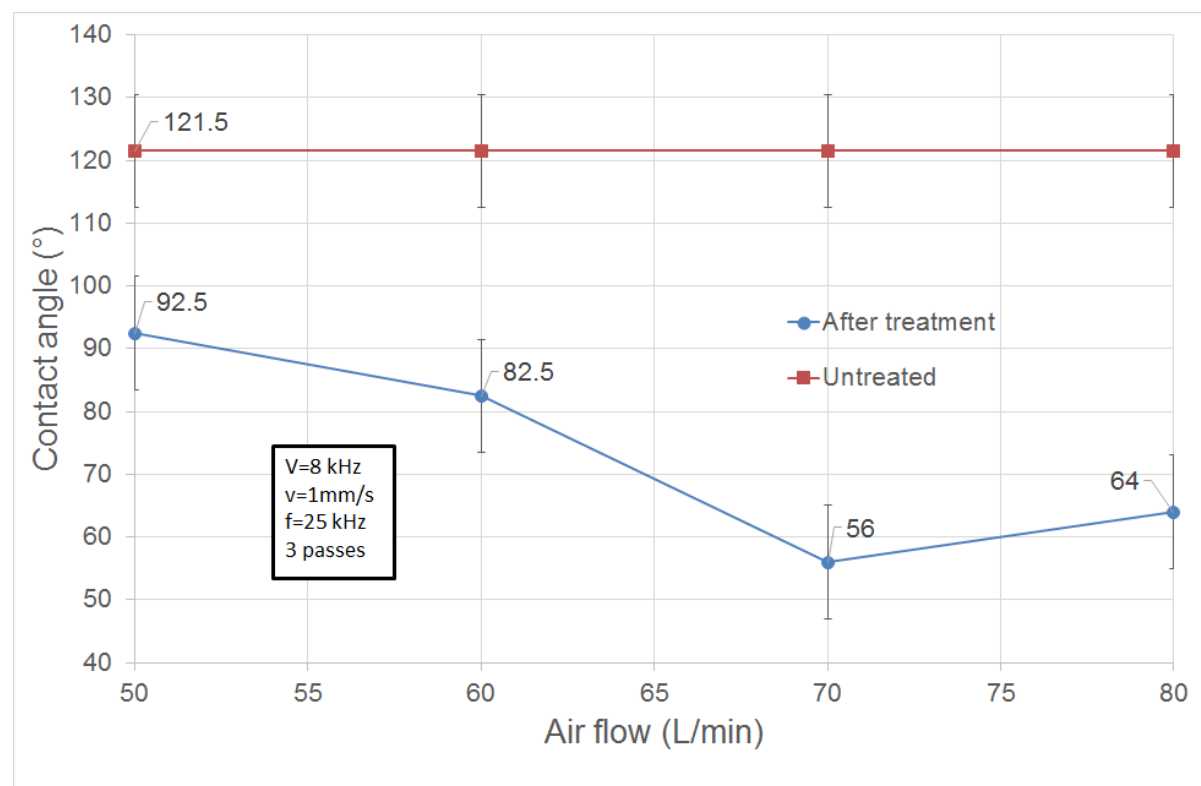

Figure 4: Influence of the air flow on the wetting properties of MDF

\begin{tabular}{|c|c|}
\hline Parameter & Value \\
\hline Voltage & $8 \mathrm{kV}$ \\
\hline Treatment speed & $1 \mathrm{~mm} \cdot \mathrm{s}^{-1}$ \\
\hline Air flow & 70 L.min $^{-1}$ \\
\hline Electric frequency & $25 \mathrm{kHz}$ \\
\hline
\end{tabular}

Table 1: Optimal values determined from the parametric study 
Thus frequency has not a large influence taking into account the uncertainties. We chose the frequency of $25 \mathrm{kHz}$ in the following for reasons related to the experimental system configuration.

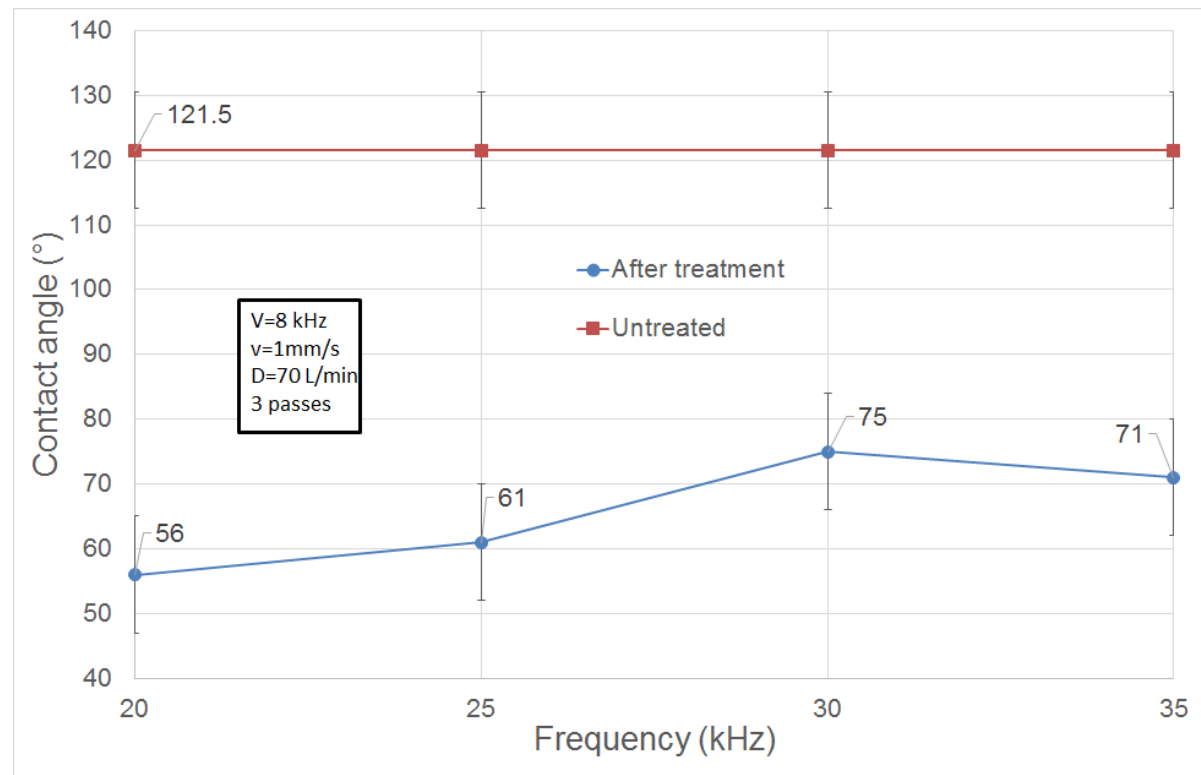

Figure 5: Influence of the electrical frequency on the wetting properties of MDF

\subsection{Surface composition}

After the first campaign of experiments and measurements, the main parameters of the process were set and summarized in Table 1. The impact of the number of sample passes under the DBD torch was finally studied. Each sample was also analyzed with XPS to determine the O/C ratio since it has been shown in many papers that this parameter is correlated to the wetting properties of MDF and wood more generally.

Figure 6 presents the evolution of the contact angle with the number of passes. As expected, the contact angle decreases with the number of passes, but it also shows that from a critical value between 2 and 3 passes, more passes do not enhance a lot the treatment. Indeed, one can see that the decrease of the contact angle is limited after 2 passes, varying from $52^{\circ}$ to $32^{\circ}$. Moreover 4 passes provide exactly the same result than 5 passes. 


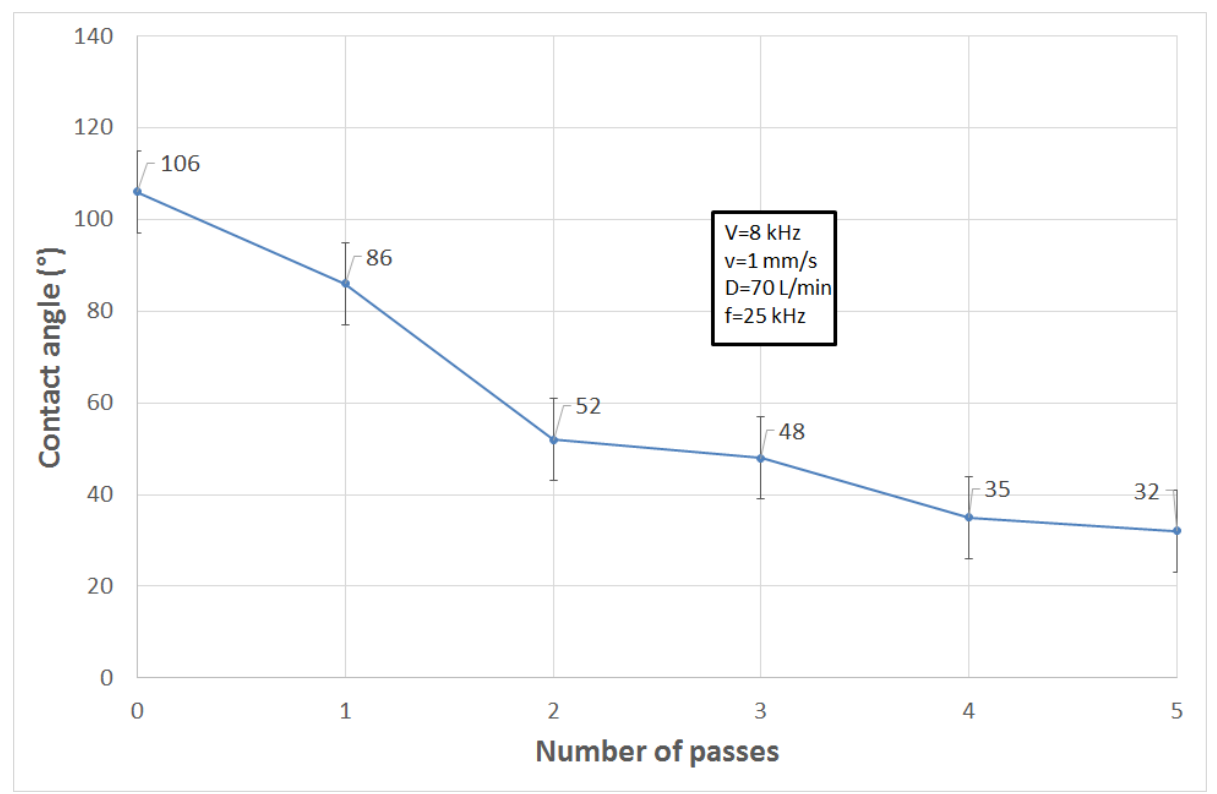

Figure 6: Influence of the passes number on the wetting properties of MDF

To support these results, XPS analyses were carried out. C1s peaks of for the untreated and 5 passes treated MDF samples are presented in Figures $7 \mathrm{a}$ and $7 \mathrm{~b}$ respectively. Figure 7a clearly shows that the untreated MDF surface is mainly composed of C-C bindings. This result is consistent with the composition of the MDF. Figure 7b highlights important changes in the composition of the MDF surface since the $\mathrm{C}-\mathrm{O}$ bindings are strongly enhanced. Moreover, the proportion of $\mathrm{C}=\mathrm{O}$ and $\mathrm{O}-\mathrm{C}=\mathrm{O}$ bonds which were weakly detected before any treatment increase also after 5 passes of DBD torch.

This behavior is supported by the results presented in Table 2 which shows the DBD torch parameters, the O1s/C1s peak ratio and the contact angles for the 5 passes. Indeed, the $\mathrm{O} 1 \mathrm{~s} / \mathrm{C} 1 \mathrm{~s}$ peak ratio increases with the number of passes highlighting an oxidation of the MDF surface.

Correlation between this surface oxidation and the resulting contact angle is presented in the Figure 8. This figure clearly shows a linear relationship between the variation of the contact angle and the evolution of the surface composition due to the DBD torch treatments.

Aging of the treated samples was also studied. The contact angle was measured just after the treatment and then regularly during twenty five days. Results are presented in Figure 9 which shows that the plasma treatment remains effective for several days. Indeed, even if there is a high increase during the first two days, the contact angle remains between $60^{\circ}$ and $80^{\circ}$ during the next 400 hours. Moreover, after twenty five 

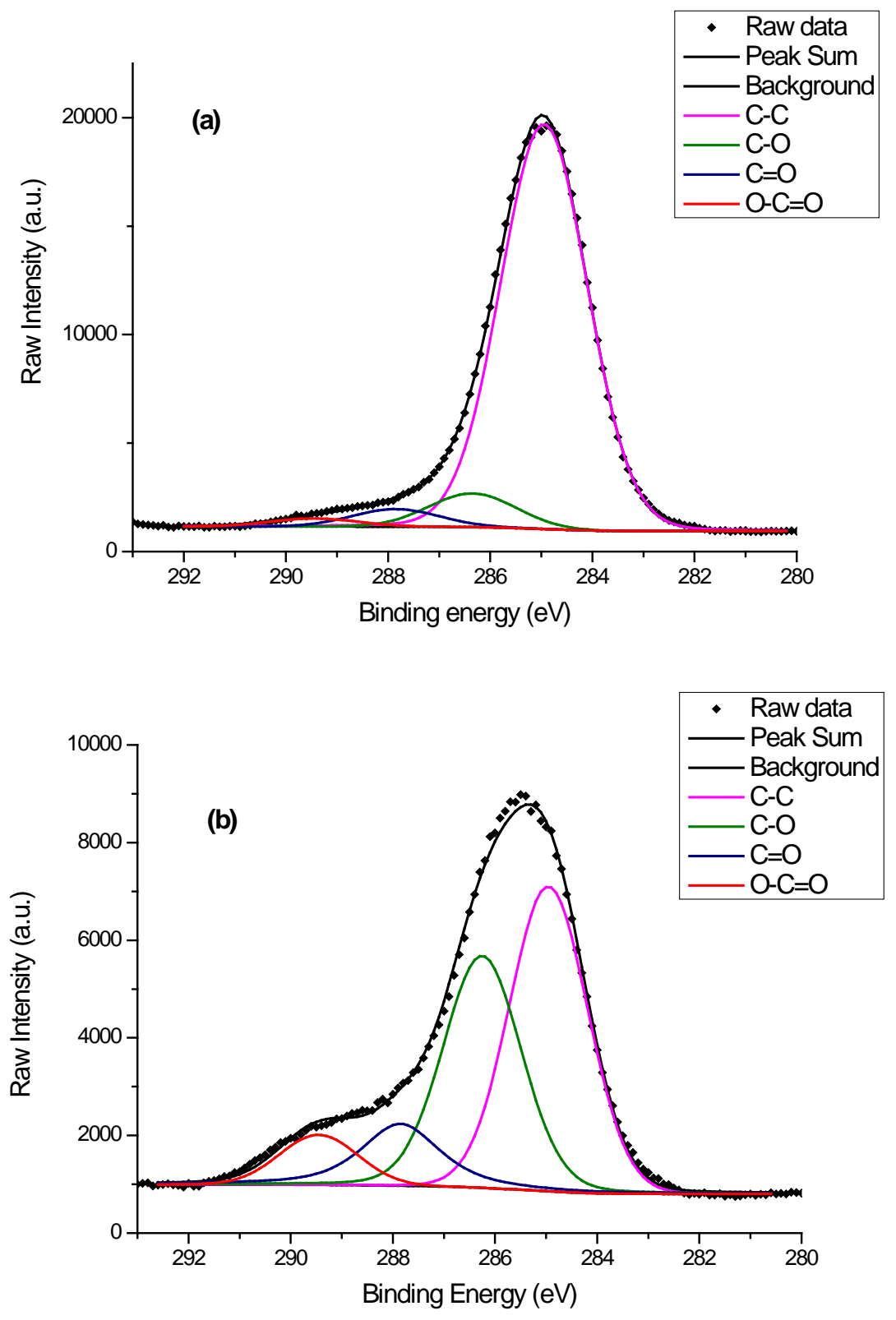

Figure 7: C1s peak measurements carried out on (a) an untreated and (b) a treated with 5 passes MDF samples 


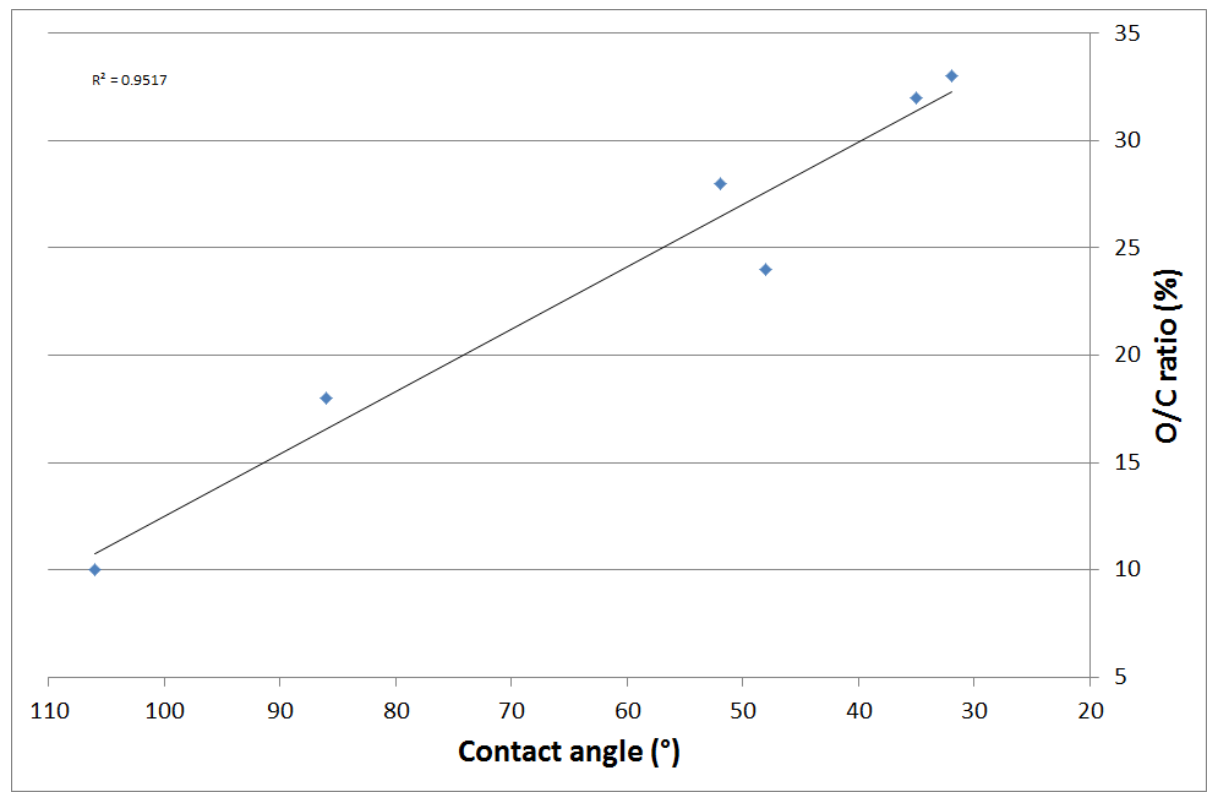

Figure 8: $\mathrm{O} / \mathrm{C}$ ratio versus the measured contact angle

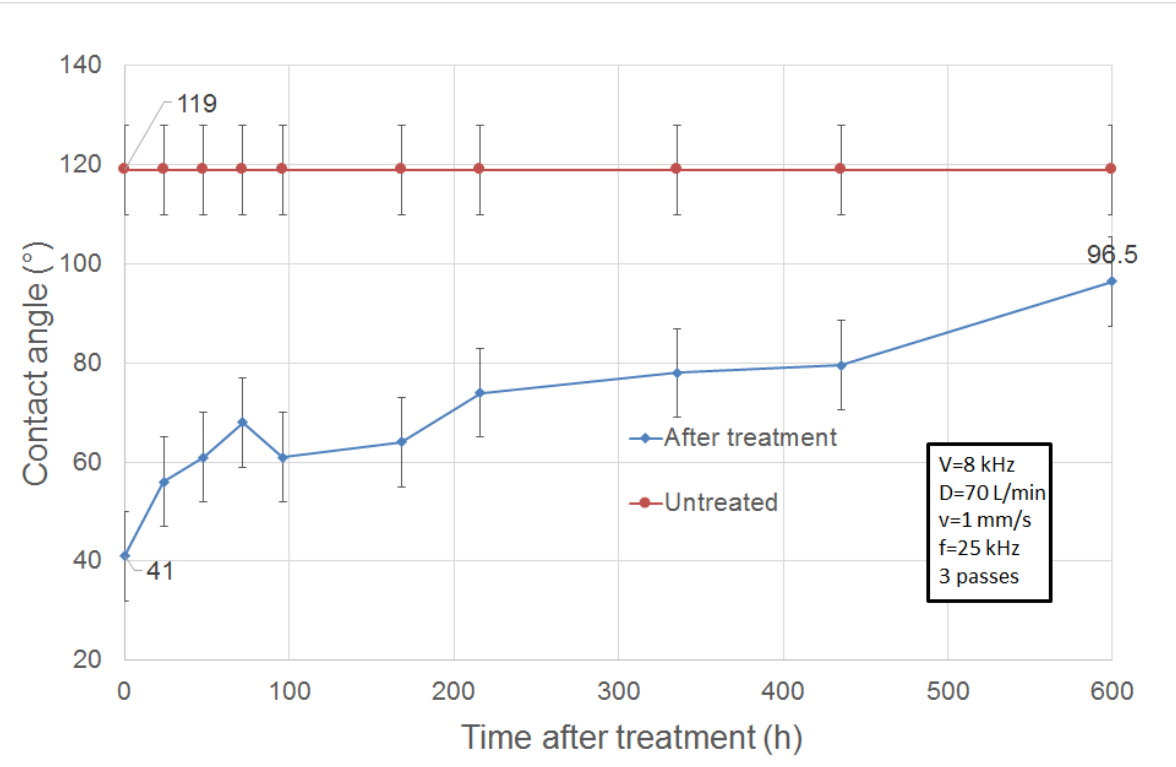

Figure 9: Evolution of wetting properties after treatment 


\begin{tabular}{|c|c|c|c|c|c|c|}
\hline Passes & $v\left(\mathrm{mms}^{\prime 1}\right)$ & $f(\mathrm{kHz})$ & $V(\mathrm{kV})$ & $D(\mathrm{NL} / \mathrm{min})$ & O1s/C1s & Contact angle $\left(^{\circ}\right)$ \\
\hline 0 & - & - & - & - & 0.27 & 106 \\
\hline 1 & 1 & 25 & 8 & 60 & 0.50 & 86 \\
\hline 2 & 1 & 25 & 8 & 60 & 0.76 & 52 \\
\hline 3 & 1 & 25 & 8 & 60 & 0.66 & 48 \\
\hline 4 & 1 & 25 & 8 & 60 & 0.88 & 35 \\
\hline 5 & 1 & 25 & 8 & 60 & 0.91 & 32 \\
\hline
\end{tabular}

Table 2: DBD torch parameters, O1s/C1s peak ratio obtained by XPS and contact angles after different passes of DBD torch treatments

days, the contact angle has not retrieved its value before the DBD torch treatment. Several processes can explain this behavior: the activation of the surface by the plasma followed by a natural oxidation of the sample or a reorganization of the surface with oxygen bulk diffusion for instance.

\section{Discussion}

The DBD torch developed allows improving MDF wettability without deteriorating it. Indeed, neither burning nor browning was observed. Logically, the higher the deposition energy, the better the efficiency of the treatment till a maximum. This efficiency has been correlated with the $\mathrm{O} 1 \mathrm{~s} / \mathrm{C} 1 \mathrm{~s}$ peak ratio at the surface. It showed that wettability is better when $\mathrm{O} 1 \mathrm{~s} / \mathrm{C} 1 \mathrm{~s}$ ratio increases. These conclusions are strongly in accordance with results of [11] referred to Wood Plastic Composites (WPC). In this case there were observes the same phenomena where decrease of peak ratio $\mathrm{C} 1 \mathrm{sA}$ responsible for $\mathrm{C}-\mathrm{C}$ and $\mathrm{C}-\mathrm{H}$ and simultaneously increase of $\mathrm{C} 1 \mathrm{sB}$ and $\mathrm{C} 1 \mathrm{sC}$ that reflect respectively $\mathrm{C}-\mathrm{O}$ and $\mathrm{C}=\mathrm{O} / \mathrm{O}-\mathrm{C}-\mathrm{O}$ bindings. Additionally with increase of energy turned out that proportions between $\mathrm{C} 1 \mathrm{sB}$ and $\mathrm{C} 1 \mathrm{sC}$ became more clear what proves increase of oxidization. When it concerned ratio of peaks correlated with oxygen according to mentioned earlier authors it is visible significant increase of $\mathrm{O} 1 \mathrm{sA}(\mathrm{C}=\mathrm{O})$ and $\mathrm{O} 1 \mathrm{sB}(\mathrm{C}-\mathrm{O})$. Moreover, with increase of deposited energy similarly as it was in case of first group of peaks, relationship between O1sA and O1sB showed progressive degree of oxidization.

Some authors such as [13] estimated in quantitative mode changes in O1s/C1s. In researches focused on analysis of extractive substances originated from wood subjected to plasma treatment it was confirmed increase of O/C ratio in case of waterborne ones from 0,39 up to 0,75 and in case of solventborne ones from 0,19 up to 0,49 .

According to [9] where influence of heat-treatment of MDF surface were examined, exist close relationship between value of $\mathrm{O} / \mathrm{C}$ and wettability properties of surface. As result of contact angle increase was poor adhesion of veneer visible in mechanical tests.

In turn, [12] proved in case of CDT (corona discharge treatment) carried out with WPC that increase of surface energy (lower contact angle) causes higher degree of oxidation. The difference in surface energy before and after modification was about $50 \%$. Analysis ATR-FTIR confirmed oxidization process.

In general, the most of works enhance the importance of oxidation process. It is worth to mention that in case of [11] appears even new functional group s such as (O$\mathrm{C}=\mathrm{O}$ ) visible in peak $\mathrm{C} 1 \mathrm{sD}$ that additionally enhance mentioned earlier process. 
Nowadays, the problem of evolution of wetting properties in time regards to seems to be more and more relevant. Fortunately, results showed in this work, in contrary to wood, are very promising. On the other hand, taking into account industry conditions this aspect of modification require more investigations. Besides, further researches that would explain how plasma treatment could improve adhesion of plastic foils, HPL/CPL laminate that are used to surface finish is indispensable.

\section{Conclusion}

This paper showed that the using of cold plasma onto MDF surface can greatly improve its wetting properties. Moreover, the durability of obtained in this way positive surface properties maintain some time after modification what could be the start point for wider usage this method in industry.

Surely, there is potential to develop a new design, more powerful to treat with higher speeds in future.

\section{References}

[1] Acda M.N., Devera E. E., Cabangon R.J., Ramos H.J., Effects of plasma modification on adhesion properties of wood, International Journal of Adhesion\& Adhesives 32, 70-75, 2012

[2] Podgórski L., Chevet B., Onic L., Merlin A., Modification of wood wettability by plasma and corona treatments, International Journal of Adhesion \& Adhesives 20, 103-111, 2000

[3] Potocnakova L., Hnilica J., Kudrle V., Increase of wettability of soft and hardwoods using microwave plasma, International Journal of Adhesion \& Adhesives 45, 125-131, 2013

[4] Rehn P., Wolkenhauer A., Bente M., Förster S., Viol W., Wood surface modification in dielectric barrier discharges at atmospheric pressure, Surface and Coatings Technology 174-175, 515-518, 2003

[5] Wellons J.D.: Adhesion to wood substrates. In ACS Symposium Series; Gould, R. F., Ed. American Chemical Society: Washington, DC, 150-168, 1977.

[6] Wolkenhauer A., Avramidis G., Hauswald E., Militz H., Viol W., Sanding vs. plasma treatment of aged wood: A comparison with respect to surface energy, International Journal of Adhesion \& Adhesives 29, 18-22, 2009

[7] Wood Handbook. Wood as an Engineering Material; United States Department of Agriculture Forest Service, Forest Products Laboratory, USDA, Forest Service: Madison, WI, 1999.

[8] Jarusombuti S., Ayrilmis N., Bauchongkol P., Vallayuth F., Surface characteristic and overlaying properties of MDF panels made from thermally treated rubberwood fibres, BioResources 5(2), 968-978, 2010

[9] Ayrilmis N., Winandy J., Effects of post heat-treatment on surface characteristics and adhesive bonding performance of medium density fiberboard, Materials and Manufacturing Processes 24, 594-599, 2009

[10] Jocham C., Sinic J., Schmidt T., Müller U., Kandelbauer A., Preparing medium 
density fiberboard surfaces for powder coating: effects of atmospheric plasma treatment, infrared irradiation, and climatization, Recent Advances in Adhesion Science and Technology in Honor of Dr. Kash Mittal Wojciech Voytek Gutowski and Hanna Dodiuk, CRC Press 2014, pp 209-226, DOI: 10.1201/b16347-16

[11] Liu Y., Tao Y., Xinying Lv., Zhang Y., Mingwei Di., Study on the surface properties of wood/polyethylene composites treated under plasma, Applied Surface Science 257: 1112-1118, 2000

[12] Moghadamzadeh H. Rahimi H, Asodollahzadeh M. Hemmati A. R., Surface treatment of wood polymer composites for adhesive bonding, International Journal of Adhesion\& Adhesives 31, 816-821, 2011

[13] Avramidis G., Klarho"fer L., Maus-Friedrichs W., Militz H, Vio“l W., Influence of air plasma treatment at atmospheric pressure on wood extractives, Polymer Degradation and Stability 97, 469-471, 2012 